\title{
Experiência e processos formativos na rede indígena de pernambuco: $O$ Pibid diversidade e as leituras decoloniais
}

\author{
Silva, Everaldo Fernandes da ${ }^{1}$ \\ Silva, Jaqueline Barbosa $\mathrm{da}^{2}$
}

\section{Resumo}

Este texto intenciona compartilhar os projetos pedagógicos e de políticas afirmativas que estão sendo vivenciados com os Povos Indígenas de Pernambuco. Essas práticas educativas que comportam iniciação à docência, pesquisa e intervenção estão sob a égide o Pibid Diversidade da Universidade Federal de Pernambuco no Campus Caruaru. O presente artigo apresenta de forma analítico-compreensiva a realização do I Seminário de estudo e socialização deste Programa da Capes, durante o mês de novembro de 2014, contando com a participação da Rede Indígena do Estado e de pesquisadores/as da ALAS (Associação Latino-americana de Sociologia). Sob os marcadores teóricos da abordagem decolonial, os relatos, os subprojetos desenvolvidos, as mesas de diálogo e as contribuições dos docentes/pesquisadores foram significativos em sublinhar as reais aproximações e imbricações entre a Educação Básica, a Universidade e a Sabedoria dos Ancestrais Indígenas.

\section{Educação Escolar indígena. Pibid Diversidade. Rede Associacionista}

\begin{abstract}
o
Este texto tiene la intención de compartir los proyectos educativos y políticas afirmativas que se están experimentando con los Pueblos Indígenas de Pernambuco. Las prácticas educativas de introducción a la enseñanza, investigación y la intervención están bajo la responsabilidad de la Universidad Federal de Pernambuco, en el Campus Caruaru, Diversidad PIBID. En este artículo presenta de forma analítica forma analítica la realización del primero seminario de estudio y socialización de este Programa Capes que pasó en el mes de noviembre de 2014, con la participación Red Indígena del Estado y los investigadores /ALAS (Asociación Latinoamericana de Sociología). Bajo los marcadores teóricos del enfoque descolonial, los informes, del subproyectos desarrollados; las mesas redondas y las contribuciones de los profesores /investigadores fueron significativos para enfatizar los enfoques actuales de la Educación Básica e de la Universidad y la Sabiduría de ascendencia indígena
\end{abstract}

Scuela de educación indígena. PIBID diversidad. Red Asociacionista

\footnotetext{
1 Doutor em educação pela Universidade Federal de Pernambuco, Mestre em Teologia pela faculdade Jesuíta de filosofia e Teologia. Professor adjunto da Universidade Federal de Pernambuco. everaldofernandes.silva@gmail.com

2 Doutora e mestra em Educação, pela Universidade Federal de Pernambuco, coordena o Programa Institucional de Bolsas de Iniciação à Docência para a Diversidade (Pibid Diversidade) /Capes. Professora Adjunta da Universidade Federal de Pernambuco. jaqueline.barbosa@yahoo.com.br
} 


\section{Introdução}

O Programa Institucional de Bolsas de Iniciação à Docência para a Diversidade, vinculado a Pró-Reitoria Acadêmica (Proacad), em desenvolvimento no Centro Acadêmico do Agreste da Universidade Federal de Pernambuco representa uma fonte de diálogo entre a Educação Básica, a Universidade e as comunidades indígenas de Pernambuco.

As ações extensionistas vinculadas a este Programa têm diferentes acentos na relação socioeducativa, desencadeando um conjunto de atividades que evidenciam o fazer escolar e a formação para a vida.

Nesta direção, o presente texto evidencia a dinâmica formativa, aprendente e paritária na construção do conhecimento, elegendo os resultados do primeiro ano de trabalho da II edição do Programa (2014-2017) ', socializados no I Seminário da Rede Indígena de Pernambuco/Il Encontro Institucional do Pibid Diversidade.

O diálogo aprendente e paritário das ações desencadeadas pelos sujeitos participantes do Programa constituíram-se num acervo de informações que aproximaram os saberes mobilizados pelas instituições de Ensino, da Educação Básica e de Ensino Superior, dos saberes advindos dos Povos Indígenas, promovendo alcances decoloniais com a participação de docentes/pesquisadores nacionais e Latino-Americanos.

\section{A Rede Indígena do Pibid Diversidade}

O projeto institucional Professores Indígenas de Pernambuco: formação, pesquisa e prática pedagógica/Área intercultural indígena do CAA da UFPE busca, na II edição (2014-2017), estreitar o diálogo Comunidade-e-Universidade e valorizar as experiências e saberes tradicionais da população indígena de Pernambuco, visibilizando os saberes formadores e propiciadores de construção do conhecimento, bem como contribuindo com a melhoria da qualidade da Educação Escolar Indígena.

O Pibid Diversidade contempla a participação dos/as Universitários/as da Educação Escolar Básica Indígena. O planejamento, acompanhamento, 
encaminhamento e sistematização das ações inclui a participação de 126 Universitários/as do Curso de Licenciatura Intercultural Indígena, vinculados à supervisão de 14 indígenas, sendo 50\% egressos da I edição do Programa, sete coordenadores de área, um Coordenador de Gestão de Processos Educacionais e uma Coordenação Institucional.

Estes Universitários/as do Pibid Diversidade encontram-se em onze Povos indígenas, são eles: Atikum, Entre Serras, Fulni-ô, Kapinawá, Kambiwá, Pankararu, Pankará, Pipipã, Tuxá, Truká e Xukuru, distribuídos em 15 municípios do sertão e agreste pernambucanosii, os quais encontram-se entre 200 e $600 \mathrm{~km}$ de distância, entre a casa e a escola, caracterizados pelos aspectos bucólicos, em sua maioria de difícil acesso, com escassez de transportes e restritos recursos tecnológicos. Essa realidade assemelha-se a de outras populações indígenas, evidenciadas em pesquisas que tomam a formação de professores indígenas do nordeste do Brasil como objeto de estudo (ALMEIDA, 2002; ALMEIDA, 2014).

Em nível nacional, o Programa conta com o apoio financeiro da Coordenação de Aperfeiçoamento de Pessoal de Nível Superior (CAPES) e o incentivo da Secretaria de Educação Continuada, Alfabetização, Diversidade e Inclusão (SECADI) na formação de professores para a educação básica e, especificamente, na formação inicial de professores nos cursos de licenciatura das instituições de educação superior.

Nesta direção, o Programa amplia o diálogo com a educação escolar indígena e enseja fortalecer a educação própria e diferenciada, contemplando ações outras que fortaleçam os saberes tradicionais e permitam o diálogo com as diferenças. Para atender esta proposição, neste primeiro ano (2014-2015), dois projetos têm permitido integrar a educação superior à educação básica, visando estreitar os distanciamentos entre a Comunidade-e-Universidade. O primeiro deles referese ao Projeto Mediação de Leitura/Centro de Estudo em Educação e Linguagem (CEEL), o qual visa, conjuntamente com o público participante, promover uma ação de formação de leitores nas escolas indígenas, subsidiando a criação e/ou estimulando a consolidação das bibliotecas comunitárias.

O segundo é o Projeto Rede Indígena que compreende o caráter formativo, aprendente e paritário dos sujeitos envolvidos, universitários-e-supervisores-ecoordenadores de área, possibilitando a todos/as estes atores/atrizes 
socioculturais descobrirem-se como sujeitos aprendentes e ensinantes simultaneamente. Nesta perspectiva, o Projeto contempla o desenvolvimento de um registro analítico-compreensivo do transcurso da formação de professores/as indígenas em seu exercício teórico-e-prático da vivência e docência dos Povos indígenas de Pernambuco. Neste Projeto, estarão inclusas, além do percurso educativo e de natureza específica, as condições de infraestrutura e da geopolítica do conhecimento presentes, local e interlocalmente dos Povos Indígenas de Pernambuco.

Os referidos projetos, instituídos no Pibid Diversidade, ampliam os subprojetos que vêm sendo desencadeados nos povos indígenas, a saber: Gestão da educação escolar indígena, Educação Inclusiva, Bem viver e tecnologias, Língua, Leitura e Produção de Textos, Arte indígena, Saberes tradicionais, e, Processos Próprios de Ensino e Aprendizagem.

Aliam-se a estas iniciativas a Comissão dos Professores Indígenas de Pernambuco (COPIPE) iii, instância de consulta e espaço político das discussões educacionais para garantir o direito e a autonomia dos Povos Indígenas de Pernambuco na construção de um projeto societário.

Esta comissão é resultante do fortalecimento dos Povos indígenas em suas históricas lutas de direitos socioculturais, em especial, a luta pelas terras e por uma educação diferenciada, específica e intercultural, em busca da valorização da cultura, da organização da escola, da história indígena revisitada, bem como da organização material e simbólica de cada Povo.

Noutras palavras, a COPIPE é um espaço político em que a luta indígena confronta-se com o Estado, impelindo-o ao respeito e valorização da cultura indígena, bem como a ampliação das políticas públicas que contemplem as especificidades e necessidades dos referidos povos. Nesta perspectiva, cada população indígena tem avançado na construção de uma escola própria e diferenciada, alavancando a autonomia dos autóctones nos espaços múltiplos e públicos das realidades sociais contemporâneas.

Soma-se a essas Redes, o Curso de Licenciatura Intercultural Indígenaiv e o Programa de Educação Tutorial (PET). No caso do Curso Superior, o diálogo entre a vida das comunidades de cada povo e a necessidade de formação para 
a docência indígena é fortalecido na relação entre a teoria e a prática e entre a universidade e as comunidades indígenas. Nessa relação, o PET, sob a tutoria de um docente, atende ao princípio da indissociabilidade entre ensino, pesquisa e extensão.

Assim, a formação em Rede acentua um processo educativo e aprendente, combatendo as múltiplas formas de colonialidade, o individualismo e as relações de poder.

\section{O Pibid Diversidade e a Visibilidade das Práticas Educativas: leituras decoloniais}

O I Seminário da Rede Indígena de Pernambuco/II Encontro Institucional do Pibid Diversidade realizado no período de 17 a 19 de novembro de $2014^{\mathrm{v}}$, vislumbrou o estreitamento do diálogo entre Comunidade-e-Universidade, dando visibilidade aos saberes formadores e propiciadores de construção do conhecimento, evidenciando o caráter formativo, aprendente e paritário dos sujeitos envolvidos, Universitários/Indígenas-e-Supervisores-e-Coordenadores de Área-e-Redes Associacionistas, destacando-se a presença de lideranças indígenas, pesquisadores indigenistas, Professores/Colaboradores do CEEL e Professores/Pesquisadores da Associação Latino-Americana de Sociologia (ALAS).

As mesas redondas, as rodas de diálogos e o cine autoral expressaram 0 caminho promissor e aprendente, construído por parte de todos/as os/as integrantes que compõem o Pibid Diversidade, movimentando-se por uma postura crítico-propositiva em termos de inculturação, de aproximação entre as intencionalidades que substanciam este Programa com as realidades complexas e específicas das populações indígenas de Pernambuco.

No período do evento em pauta, os percursos socializados pelos Povos indígenas anunciaram a dinâmica do trabalho, evidenciaram novas aprendizagens, bem como demostraram as riquezas culturais destes povos nativos e, simultaneamente, desafiados perante as insistentes constatações da ausência das políticas públicas nas questões etnicorraciais locais e regionais. 
A socialização das experiências gestadas in loco evidenciou as reflexões e ações desencadeadas na Educação Básica, além de elucidar novas temáticas, ampliando os conhecimentos acerca de uma Educação Escolar Indígena específica e diferenciada. Dentre as ações apresentadas, destacam-se:

O subprojeto Bem Viver e Tecnologias, vivenciado no Povo Truká, evidencia o caráter sociocultural e humano, ampliando a forma de olhar o Rio São Francisco, enquanto fonte de vida do Povo Truká e de todos os ribeirinhos que se encontram à margem deste rio no Estado de Pernambuco.

A socialização do vídeo/documentário, no cine autoral, produzido pelos sujeitos envolvidos neste subprojeto, deu visibilidade a elementos da natureza característicos do Povo, evidenciando a dualidade complementar entre o "bem da vida" e o "viver bem". Ou seja, o "bem da vida" é representado pela manutenção do rio, o qual fortalece a sobrevivência dos Povos indígenas e ribeirinhos ofertando-Ihes diversas formas de sustento material e simbólico. Por outro lado, o "viver bem" anuncia a gravidade de um contexto que privilegia as práticas mercadológicas, denunciando que o não cuidado com a preservação da natureza acarreta um problema gravíssimo para os indígenas e os não indígenas do território pernambucano,

[...] o sangue que nos alimenta "tá" contaminado (Universitário e bolsista do Pibid Diversidade/Liderança do Povo Truká de Orobó/PE).

[...] matando o rio, as pessoas que dependem dele vão juntas (Cacica do Povo Truká de Orobó/PE).

Nestes depoimentos, sublinhamos que o projeto intervencionista Origem, cultura e a sobrevivência do Povo, põe em relevo a vida simbólica e material do Povo, seja refletindo a importância dos valores dos Povos indígenas, especificamente no que diz respeito à forma de vida diferenciada do "mal viver" da sociedade ocidental; seja elucidando o lugar da educação escolar indígena própria, dando assento à cultura e às formas de vida e de saberes desses povos.

- O subprojeto Gestão da Educação Escolar Indígena atende aos Povos Pankará e Pipipã e trabalha a gestão da educação escolar indígena, atendendo ao princípio da interculturalidade. 
O vídeo/documentário exibido no cine autoral apresentou a relação entre o conhecimento acadêmico em horizontalidade com os conhecimentos dos Povos.

Enquanto instrumento audiovisual, o texto exibido deu visibilidade ao cenário geográfico das comunidades indígenas, Pipipã e Pankará, bem como evidenciou a concepção de educação coletiva na organização da gestão escolar indígena, enfatizada nos depoimentos dos que fazem a comunidade indígena, lideranças, cacicado, pajés, professores/as.

- O subprojeto Educação Inclusiva, dos Povos Pankararu e Entre Serras, contempla uma série de atividades dirigidas à Educação Básica da educação escolar indígena. Apesar da educação inclusiva não ser uma discussão nova, traz desafios e exige um novo pensar/olhar sobre o tema, entre outros por ter "[...] muitas crianças especiais nas aldeias" (Supervisora de Área do Pibid Diversidade/Povo Pankararu).

Ao contemplar ações integradas que vislumbrem a perspectiva da transdisciplinaridade, o referido subprojeto possibilitou diagnosticar quem são os sujeitos com deficiências e quais os tipos de doenças. Após esse diagnóstico o estudo dos marcos legais da educação inclusiva aliou-se ao projeto Mediadores de Leitura, promovido pelo CEEL, articulando ações que possibilitassem a alfabetização das crianças com deficiência.

Nesta direção, a meta é criar uma biblioteca itinerante, acessível a comunidade, efetivando a consolidação do processo de alfabetização das crianças com deficiências.

- O subprojeto Língua, Leitura e Produção de Textos, em desenvolvimento no Povo Xukuru, proporciona orientações acerca do processo de aquisição do sistema de escrita e de desenvolvimento das habilidades de uso da escrita, na escola indígena. O foco nas atuais concepções sobre a aprendizagem da língua escrita e, consequentemente, sobre o seu ensino oportunizou, aos/as Universitários/as indígenas, a discussão e elaboração de projetos intervencionistas sob diversas temáticas, tais como: a medicina tradicional do povo Xukuru: um encantamento pela leitura e escrita através da ciência dos mais velhos; Ler e escrever a partir das histórias e experiências dos mais velhos; Jogos e brincadeiras do Povo Xukuru; A cultura material e simbólica do Povo Xukuru; Histórias e Mitos do Povo Xukuru; Pintura corporal Xukuru; Histórias contadas pelos toípes: um instrumento de fortalecimento da identidade étnica e facilitador do processo de leitura e escrita; A geografia Xukuru; A Igreja Católica e a 
Resistência Xukuru; Um olhar histórico para o nome do nosso povo e aldeias: ler e escrever através dos nomes e seus significados; Educação Xukuru na escola: a interdisciplinaridade a partir dos saberes do povo; Um olhar histórico para o nome do nosso povo e aldeias: ler e escrever através dos nomes e seus significados; Cuidando da mãe natureza, os opip Xukuru reciclando e recriando; As histórias do Povo Xukuru contadas e recontadas pelos Toíopes e A leitura que dá frutos.

As ações intervencionistas imbricam-se na vida do Povo Xukuru, transcorrendo as identidades individuais e coletivas, bem com suas práticas educativas. A educação Xukuru, nesta esteira da memória coletiva, dá-se na relação da própria comunidade com os mais velhos e na interlocução com o sagrado que se comunica através dos segredos da natureza interpretados pelo Pajé. Neste contexto socioeducativo, a educação escolar deste Povo consolida-se com as contribuições da formação dos professores na perspectiva decolonial. $\mathrm{Na}$ apresentação do Seminário, tiveram espaços as crenças e místicas do Povo.

Na roda de diálogo sobre a produção Textual na Educação Escolar Indígena, a compreensão dos mitos adquiriu força, contrariando as imagens de mentira, de crendices, de compreensões mágicas e ilusórias do real. Isto se deu à medida que a abordagem racionalista e cartesiana, sob a pretensão de verdade científica, foi tomando proporções expressivas nas leituras de mundo transmitidas nas escolas e na mídia. Na mentalidade Xukuru, os mitos são narrativas que manifestam verdades existenciais e legitimadoras das suas autoidentidades, portanto, fornecem referenciais coletivos e imemoriais que forjam as referências basilares do ser e das lutas do Povo Xukuru.

- O subprojeto Arte indígena, vivenciado pelo Povo Kambiwá, ao proporcionar a ampliação do debate e compreensão sobre o ensino de arte, buscou contextualizar a educação escolar indígena do Povo Kambiwá, seja registrando a arte indígena vivenciada na educação escolar do Povo, seja procedendo a orientação do planejamento de estratégias reflexivas que promovessem o intercâmbio de experiências entre os Povos.

Neste subprojeto, a metodologia utilizada consistiu no diálogo permanente entre os sábios da comunidade e as novas gerações, mediado pelo/a professor/a, ao mesmo tempo, que a confecção dos artefatos artístico-culturais também se dava 
paritariamente. Deste modo, o fazer conjunto e compartilhado retrata a marca predominante do caminho ensinante e aprendente desse grupo étnico.

A aprendizagem dos conhecimentos artísticos a partir daqueles/as que produzem a arte no Povo Kambiwá evidenciou a inter-relação entre o fazer, o ler e contextualizar arte, desafiando o/a professor/a indígena a ser pesquisador de sua arte.

Assim, o Povo Kambiwá tem reafirmado sua identidade étnico-cultural no processo de construção do conhecimento artístico, seja contribuindo através dos registros escritos da produção artística, seja preservando a identidade étnica através da presença e depoimentos no âmbito escolar daqueles/as que fazem a arte no Povo.

- O subprojeto Saberes tradicionais, presente nos Povos Atikum e Fulni-ô, elegeu a temática Arte-artesanato como fortalecimento da identidade indígena, dando destaque à literatura infanto-juvenil indígena desses povos e à descrição do processo de coleta da matéria-prima na confecção das produções artísticas, enfatizado, sobremaneira, pelo Povo Fulni-ô. O conjunto de entrevistas, realizadas com os artesãos e artesãs dos referidos povos, adquiriu proeminência nos espaços e presenças comunicantes.

Assim, o artesanato Fulni-ô, especificamente, descobre-se nesta rota etnológica e simbólica a sua maneira própria de autoexpressão, socializado no vídeo: $A$ identidade Fulni-ô através da Arte.

O Pibid Diversidade viu-se neste caminho contribuinte, socializando o passo a passo da fabricação dos materiais artístico-culturais, ao mesmo tempo, em que sinaliza a escassez da matéria prima e a não continuidade do processo de fabricação artesanal, de alguns dos artefatos, pelas novas gerações.

[...] a arte nasceu como uma necessidade de caracterizar seu povo, para dar identidade. A natureza é quem dá direcionamento para as práticas cotidianas. (Supervisora de Área do Pibid Diversidade/Povo Atikum).

Outrossim, a Educação Escolar Indígena assume a função de afirmação das identidades éticas, seja recuperando as memórias históricas, seja valorizando as 
linguagens e (re)conhecendo sua arte/artesanato na revitalização da relação entre escola/sociedade/identidade.

- O subprojeto Processos Próprios de Ensino e Aprendizagem contempla os Povos Kapinawá e Tuxá e vem aprofundando o autoconhecimento das aprendizagens e ensinagens indígenas enquanto instrumento de fortalecimento da identidade cultural.

Nestes Povos, as atividades têm obedecido às diferentes metodologias: as rodas de diálogo e aulas práticas, reunindo lideranças e a comunidade escolar, passando pela leitura e estudos dirigidos sobre conteúdos relacionados à temática dos processos próprios de aprendizagem. Este percurso da construção também inclui a realização de oficinas e feiras de conhecimentos nas escolas. Um ponto importante a ser sublinhado, em termos metodológicos, é a participação de lideranças (envolvidas diretamente ou não com a comunidade escolar) no planejamento das atividades/ações. A integração das atividades coletivas é presentificada no ensino de história, geografia, matemática e língua portuguesa, privilegiando o tempo histórico, os métodos e as técnicas desenvolvidas ancestralmente pelos indígenas das aldeias, principalmente pelos que não tiveram acesso à escola.

Assim, a revalorização dos processos próprios de ensino e aprendizagem, bem como da cultura local, através da presença das lideranças nas atividades escolares, tem sido fundamental para a reafirmação da identidade cultural dos povos. Este caminho é traçado entre as escolas das aldeias e os sábios da comunidade.

Ao favorecer uma clareza a respeito da função social da escola indígena, o subprojeto tem favorecido uma melhoria no que tange à organização do trabalho docente dos/as bolsistas Universitários/as, preocupando-se com o que fazer, como fazer, que material utilizar e como estabelecer um diálogo entre a cultura indígena e não indígena, afim de eximir, entre outras, "[...] as dificuldades dos saberes matemáticos na sala de aula das aldeias" (Supervisora de Área do Pibid Diversidade/Povo Tuxá). Ou seja, buscam-se "[...] estratégias para que o ensino/aprendizagem sejam realizados com sentidos" (Supervisora de Área do Pibid Diversidade/Povo Tuxá). O foco do valor da terra e das memórias do povo exemplificam algumas das ações intervencionistas nos Povos Tuxá e Kambiwá. 
Ao vislumbrar as ações na ótica dos Povos originários, os pesquisadores da ALAS, presentes no evento, partilharam suas impressões, instituindo um destaque das ações desencadeadas pelo Pibid Diversidade nos Povos indígenas de Pernambuco.

O fio articulador, ser indío-a/ser Professor-a/serUniversitário-a, visibiliza a aldeia, enquanto Universo de socialização de saber na relação com a Universidade e a vida. Ou seja, a importância de se ter o índio como professor dentro das aldeias, a necessidade de se ter mediadores para o diálogo entre os Povos indígenas e a realidade global e o próprio modo de vida dos Povos como fonte de saberes, de enunciação. Para a professora/pesquisadora Maria da Glória Gohn, da Universidade de Campinas (UNICAMP), o aprender fazendo, do índio professor, torna-o agente/autor de sua história, dando um destaque ao alcance significativo das experiências socializadas pelos pibidianos e pelos coordenadores de área. Para Milton Vidal Rojas, Secretário da Presidência da ALAS/Chile, o Pibid Diversidade na Universidade faz evidenciar as especificidades dos Povos indígenas, anunciando suas necessidades, respeitando suas diferenças e reconhecendo, nestes Povos, seu lugar no mundo social, enquanto sujeitos de direitos.

\begin{abstract}
Está claro que ainda se tem muitas necessidades. Não há um respeito às línguas desses povos no meu país. No Chile, a educação formal assiste à população mais carente. A educação deve ser parte do bem viver também (MILTON VIDAL ROJAS/ Secretário da Presidência da ALAS/Chile).
\end{abstract}

Essa perspectiva do diálogo e reconhecimento do sujeito aprendente, segundo Milton Vidal Rojas "assusta professores conservadores". De inspiração Freireana, essas perspectivas rompem com as relações hierárquicas, investindo no ser diferente, nas práticas cordiais, desafiando os "direitos iguais e direitos diferentes respeitando os iguais" (Milton Vidal Rojas).

Essa maneira de conceber a experiência formativa sublinha a existência do respeito no processo formativo entre os indígenas, destacando que neste processo todos são considerados intelectuais, sujeitos epistêmicos. E, nesta direção, assumindo o projeto decolonial, somos todos índios (Adrian Oscar Scribano/Conicet/Argentina). 
Em outras palavras, na formação do sujeito aprendente desafia-nos a integração cultural entre os Povos indígenas e os sujeitos não indígenas, anunciando diversas pedagogias, entre elas: da leitura, da pintura, da escrita e da música. Ou seja, "o desafio é mover diversas pedagogias" (Angeli de Sena UBA/Argentina).

Os atores envolvidos com a Rede Indígena, ao anunciarem outras pedagogias, apontam para outra ideia de tempo, rompendo com o cronológico. Pois, os modos de vida daqueles e daquelas que se mantém afastado do Centro, anuncia uma territorialidade e uma temporalidade que privilegia a história de vida dos sujeitos e suas características e ritmos próprios.

As experiências em foco revelam a dinâmica do pensar e fazer a educação escolar indígena, configurando-se em identidades próprias e práticas organizativas decoloniais situadas entre as forças do Estado e os imperativos do Mercado. Assim, o conjunto destas ações coloca em proeminência a visibilidade da educação escolar indígena e anuncia os desafios e emergência da garantia de políticas públicas de direitos essenciais para a manutenção material, simbólica, identitária, econômica, histórica, geográfica e social dos Povos indígenas.

A conquista de espaços para dialogar e estreitar a relação entre os indígenas e não-indígenas evidencia a visibilidade dos grupos minoritários.

Na secretaria da educação se trava uma batalha necessária para o fortalecimento da educação escolar indígena. Dentro da universidade enxergamos outras necessidades. O Pibid Diversidade, nesta relação, vem promovendo um diálogo importante. Porém, desenvolver ações escolares é uma missão de todos. (Universitário e bolsista do Pibid Diversidade/ Liderança do Povo Truká de Orobó/ PE).

A alavanca do diálogo foi acionada e, neste movimento, emerge outras necessidades, tais como, a de pensar a ampliação da oferta de Curso Superiores para valorização da fauna e da flora, destacando, bem como, os Cursos de medicina e engenharia que contemplem os saberes tradicionais e locais.

Articular-se em Redes foi uma necessidade para a manutenção dos Povos diferenciados. O Estado via os indígenas como cultura de transição, estariam introduzidos no espaço brasileiro, abdicando nossa cultura. Assim, nascem movimentos como o 
movimento indigenistas: pedagogos, professores, unidos e trabalhando com os Povos indígenas para a afirmação e recuperação da cultura (Indigenista/ Docente/Pesquisadora Eliene Amorim de Almeida).

A educação, como sendo a reflexão sobre a própria vida, tem assento nas socializações, diálogos e debates, propondo a abertura de novos mundos, novas ações, novas formações, em que o Toré, ritual sagrado que representa todos os Povos de Pernambuco, anuncia uma nova prática, convidando os sujeitos a inserirem-se no coletivo.

Assim, ao longo do evento, seja realizando a abertura das atividades, seja finalizando-as, o Toré instalou-se com o intuito de proporcionar o fortalecimento da identidade, agradecer e comemorar a possibilidade do encontro. Neste ritual, o cântico do "toante" contemplou as etnias indígenas de Pernambuco e foi experienciado pelos participantes, indígenas e não indígenas.

Estas leituras, dos modos próprios de produzir e de gerir a metodologia/epistemologia das ações do Pibid Diversidade, entrecruzaram-se com as contribuições dos Estudos Pós-coloniais Latino-Americanos (MIGNOLO, 2007; MALDONADO-TORRES, 2007; SILVA, SILVA e SILVA, 2014) que propõem a "desnaturalização" dos olhares viciados pela modernidade, pela colonialidade e pelo capitalismo, trazendo para a convivência escolar a comunidade, a ancestralidade, a territorialidade e o sagrado.

Nestas ações, as escolas passam a ser espaços produtores de reflexão, as aldeias tornam-se campos de vivências e de ensinagens e os anciãos representam as fontes de pesquisa, em que os sujeitos aprendentes substituem a leitura das condições de vida de subalternizados por posturas autoafirmativas em relação à história local e à identidade indígena.

\section{O Pibid Diversidade Para Além Da Extensão: Considerações} Finais

O Evento em pauta disponibilizou-nos os alcances das iniciativas socioeducativas que dão vida própria as Redes Associacionistas, tanto em termos autoidentitários, quanto nas contribuições formativas entre os espaços educacionais escolares e não escolares. 
As redes associacionistas, que estão presentes na luta dos Povos indígenas e que contribuem com o Pibid Diversidade, representam uma história construída em meio às contradições, nas lutas dos movimentos sociais. Logo, compreendemos que as Redes alcançam o Estado, o social e o imaginário da competitividade. O imaginário social tem, silenciosamente, desmantelado as redes, silenciando-as do cotidiano das TVs, ausentando seu alcance da população em geral, internalizando, via cultura do consumo, um imaginário único e padronizado do ser humano e das classes sociais.

O Estado nacional ao mascarar a perspectiva do Estado pluricultural restringe as fronteiras do saber/conhecimento. E, a reeducação do olhar, ajuda no deslocar da visão dualista de ser humano. O saber/o conhecimento é o corpo todo, não é só a cabeça/o guardar na mente, não fica no campo da mente, mas acomete todo nosso corpo. Ela faz parte da nossa autocompreensão, da nossa corporeidade e dos nossos modos de ser e estar no mundo. Assim, o conhecimento amplia fronteiras, alargando-as, não ficando restrito aos espaços escolares e às teorias especulativas. A questão tempo passado/futuro ultrapassa a cronologia internalizada pelo nosso ser, passando a compor uma relação de convivência e percepção ativa que atribui sentido a um novo modelo de mundo. Com este entendimento das práticas cognoscentes, as redes como um meio de ajudar a destruir esse olhar viciado/colonial/superior, internalizado pelas padronizações que excluem o diferente, anunciam formas outras de construção do conhecimento, contemplando, entre outras: a observação, a intuição e a orientação dos encantados. A história que nós conhecemos hoje se construiu em meio às contradições e diferenças dos movimentos. A ideia do "cuidar de si mesmo" cultivada pela sociedade capitalista, não resiste ao princípio da coletividade. Pois, na dinâmica de vida dos Povos indígenas, retirar-se do coletivo, se isolando, significa o extermínio sociocultural.

A vida como espaço pedagógico descoloniza o olhar, fortalece o intercâmbio entre as redes, possibilitando as trocas de saberes em espaços diversificados (institucionais ou não). A conversa entre os Povos indígenas, a América Latina e outros continentes, vislumbrados de acordo com os interesses dos Povos, 
potencializa a utilização de estratégias que denunciam o imaginário individualista e competitivo do mercado neoliberal.

O evento apontou a necessidade de manutenção das redes associacionistas, disponibilizou um acervo de depoimentos e informações que estreitaram os saberes entre o Ensino Superior-a Eeducação Básica-e-os Povos indígenas, bem como produziu reflexões nos indivíduos participantes, permitindo, de um lado, a rememoração dos saberes tradicionais, e, do outro lado, o estranhamento individual e coletivo das práticas educativas.

A gratidão explícita na rememoração da vida, nas ações desencadeadas pelo Pibid Diversidade, anuncia a necessidade de fortalecimento social diante da mercadorização da vida, desafiando as estratégias de enfrentamento do cotidiano perante a coletividade, a globalização e o poder do Estado nacional.

Por fim, o saber/conhecimento propiciado no processo de construção paritária entre os espaços/sujeitos institucionais e a comunidade indígena deu visibilidade à identidade coletiva dos Povos indígenas do agreste e do sertão pernambucanos. Este seminário significou resistência identitária, socialização de iniciativas coletivas em prol do fazer valer a histórica presença e contribuições de grande parte dos indígenas do nordeste do Brasil.

\section{Referências}

ALMEIDA, Eliene Amorim de. A política da Educação Escolar Indígena: limites e possibilidades da escola indígena. Dissertação de Mestrado, Programa de Pós-Graduação em Educação da UFPE, Recife/PE, 2002.

ALMEIDA, Patrícia Fortes de. Currículo em "Movimentos" a constituição do saber escolar pelos índios Pankará da Serra do Arapuá - PE. . Dissertação de Mestrado: UFRN, 2014.

MALDONADO-TORRES, Nelson. Sobre la colonialidad del ser: contribuicones al desarrollo de um concepto. El Giro Decolonial: reflexiones para una diversidade epistémica más allá del capitalismo global. Bogotá: Siglo del Hombre Editores, 2007.

MIGNOLO, Walter. El Pensamiento Decolonial. El Giro Decolonial: reflexiones para una diversidad epistémica más allá del capitalismo global. Bogotá: Siglo del Hombre Editores, 2007. p. 25-46.

SILVA, Fátima Aparecida da; SILVA, Jaqueline Barbosa da; ALMEIDA, Eliene Amorim de. Diversidade e educação escolar indígena em Pernambuco: o Programa Institucional de Iniciação à Docência no contexto da UFPE. Reflexões e ações sobre educação, estado e diversidade. $2^{\mathrm{a}}$ ed., Recife/PE: Editora UFPE, 2014.

SILVA, Janssen Felipe da; SILVA, Everaldo Fernandes da; SILVA, Jaqueline Barbosa da. Educação Populares e Movimentos Sociais nas Crises da Modernidade: um olhar através dos Estudos Pós-Coloniais. Lumen, v. 23, n. 1, jan./jun., 2014. p. 09-26. 
' Para conhecer o alcance e dinâmica metodológica da I edição do Pibid Diversidade acessar Silva, Silva e Almeida (2014).

ii Águas Belas, Buíque, Cabrobó, Carnaubeira da Penha, Floresta, Ibimirim, Inajá, Jatobá, Orocó, Pesqueira, Petrolândia, Poção, Salgueiro, Tacaratu e Tupanatinga.

iii Esta Comissão foi criada em 1999, sob a iniciativa do Povo Xukuru e constituída por dois professores indígenas e lideranças de cada Povo. Ela representa, no movimento indígena, a luta pela educação escolar específica e diferenciada, tendo sua missão materializada na conquista de políticas públicas que visam um projeto societário. Essa comissão prima pela autonomia dos Povos indígenas de Pernambuco, viabilizando as lutas pela garantia e conquista de espaço autonômico, político e democrático.

iv Aprovado em 2008 pelo Edital 01 do PROLIND/MEC/SESu, tendo suas atividades iniciadas no ano de 2009. O Curso, desencadeado pelo Centro Acadêmico do Agreste da UFPE, é destinado à formação dos professores indígenas que atuam na Educação Básica, particularmente, nos anos finais do ensino fundamental e ensino médio em escolas indígenas.

$\checkmark$ O evento foi sediado no hotel Canariu's, localizado em um dos municípios do agreste pernambucano, a saber: Gravatá/PE. 